\title{
A transposição demolida antes de começar
}

प EAN-PAUL SARTRE, o filósofo francês, está saindo da moda. Mas já na década de 1950, antes que os ambientalistas modernos começassem a demonstrar as relações entre todos os elementos que fazem parte da vida, Sartre escrevia que a descoberta fundamental de sua carreira de pensador havia sido a de que a solidariedade não constitui apenas um dever moral; é um fato, puro e simples, gostemos ou não, queiramos ou não. E essa descoberta fundamental ele a fizera em um campo de prisioneiros mantido na França pelos nazistas, durante a Segunda Guerra Mundial. Ali, preso, inerme diante de seus carcereiros, Sartre concluíra que sua vida dependia concretamente de seus algozes, que poderiam terminar com ela a qualquer momento, se o desejassem; mas também a vida deles, carcereiros, dependia do prisioneiro: se ele conseguisse fugir, deixá-los-ia em palpos de aranha, sujeitos até a fuzilamento. Eram, portanto, todos, solidários.

E assim é, tudo depende de tudo, todos dependemos de todos. Metaforicamente, tem-se afirmado que, se se conseguisse pesquisar toda a cadeia de acontecimentos, verificar-se-ia que o bater de asas de uma borboleta na China pode desencadear chuvas caudalosas no outro lado da Terra. Ignorar o conjunto de causas e a seqüência de fatos pode, por isso, dar origem a erros muito graves.

Essa é uma das lições principais do livro Os descaminhos do São Francisco, que o jornalista Marco Antônio T. Coelho acaba de publicar pela Paz e Terra, com prefácio do ex-ministro, atual secretário de Meio Ambiente e Desenvolvimento
Sustentável de Minas Gerais, José Carlos Carvalho e ilustrações de Maria Helena Andrés. Ele mostra, irrefutavelmente, que o atual projeto de transposição de águas do Rio São Francisco, tal como seus antecessores, não leva em consideração as razões históricas, políticas, econômicas e sociais da situação do semi-árido nordestino e da bacia daquele rio, da mesma forma que parece desconhecer as realidades morfológicas, hídricas, climáticas, geográficas, paisagísticas e humanas das duas regiões . Por isso, por desconsiderar que tudo está relacionado com tudo e propor "soluções" isoladas, parciais e alienadas, está fadado ao fracasso - político ou na prática, se vier a ser implantado.

Já na "orelha do livro", o Prof. Antônio Carlos R. Moraes, do Departamento de Geografia da Universidade de São Paulo, lembra que "a ótica territorialista e colonial é bem explicitada nos planos e usos das águas do rio São Francisco". A seu ver, "a classe dominante brasileira sempre olhou o país como quem observa um espaço para se apropriar e gerar riquezas para seu usufruto. Raras vezes o observou como um povo, uma nação ou uma sociedade". Por essa óptica, "os brasileiros eram concebidos como instrumentos ou entraves à geração de riqueza, meios de acumulação ou obstáculo à modernização produtiva pretendida". Com o atual projeto de transposição, não estaria sendo diferente.

Também o ex-ministro e atual secretário José Carlos Carvalho é contundente em seu prefácio. $\mathrm{O}$ processo em curso, pensa ele, "coloca em xeque perigosamente o modelo de gestão de recursos 
hídricos" previsto na Lei 9.433/97, que consagra "a gestão descentralizada e participativa no âmbito regional e limita decisivamente o grau de arbítrio por parte do Poder Executivo". Porque o governo federal, que, sozinho, tem maioria no Conselho Nacional de Recursos Hídricos, prevaleceu-se dessa impropriedade da lei para aprovar o projeto de transposição de águas, contrariando decisão em sentido oposto da maioria esmagadora dos membros do Comitê de Gestão da Bacia Hidrográfica do Rio São Francisco. Onde fica o princípio básico da lei? E o princípio federativo?

O secretário José Carlos Carvalho também considera decisivo, para chegar a uma proposta adequada no caso, examinar o processo histórico da região, as causas do subdesenvolvimento - principalmente nas regiões mais pobres, como o semiárido -, que não estão associadas direta e exclusivamente à disponibilidade de recursos hídricos, mas ao processo de ocupação desses territórios, com desníveis educacionais e de renda da população, à inexistência de projetos de desenvolvimento de longo prazo e aos desequilíbrios regionais, que sempre trabalharam, na região, para perpetuar a pobreza e a chamada indústria da seca.

\section{Para que serve o rio?}

É exatamente a trilha seguida pelo livro. Para seu autor, "impunha-se uma revisão substancial nas análises a respeito do grande rio", que foi reduzido à condição de um canal a serviço da produção de energia elétrica. "Desapareceram os vapores e as barcas com as carrancas, sumiram os cardumes de surubins e dourados [...] dissolveram-se nas brumas do passado os fantasmas dos coronéis [...] assim como as matriarcas." O Velho Chico "só não virou um retrato na parede porque suas águas são eternas e dia e noite movimentam as gulosas turbinas".

Com essa melancolia de um mineiro que já consagrou outro livro a outro rio, o das Velhas, Marco Antônio Coelho, para não cair na tentação de esquecer-se de todos os relacionamentos, vai começar sua pesquisa na lenda da índia Yati, cujo noivo, guerreiro, morrera em combate com outra tribo. Yati chorou tanto que suas lágrimas formaram o São Francisco no Chapadão da Zagaia, Serra da Canastra.

Talvez por essa origem, começando num chapadão indelevelmente ligado às origens da colonização no Brasil, "nenhum outro dos nossos grandes rios influenciou tanto o país" e acabou conhecido como "o rio da unidade nacional". Ele presenciou os massacres de grupos indígenas, "que passaram a ser expulsos de suas terras, mortos ou escravizados pelos 'descobridores' do território" - um dos "capítulos mais tenebrosos da colonização lusitana”. Presenciou o avanço da pecuária na região. Presenciou a corrida dos bandeirantes paulistas para as jazidas de ouro do Rio das Velhas. E, "sendo a porta de entrada para o território das minas e de todo o interior, ele também foi a rota para serem atingidos os campos do Piauí e do Maranhão, assim como as bacias do Tocantins-Araguaia e do Paraná". O autor cita as observações de Vicente Licínio Cardoso em 1925: "Sem aquele rio, sem aquela estrada natural interior, teria sido impossível manter a unidade da nossa pátria".

Outro historiador, Wilson Lins, atribui a redução da importância do São Francisco, a partir do século XVIII, à decisão das autoridades portuguesas de "determinar um 'caminho novo' entre as minas de ouro e o Rio de Janeiro; o segundo 
fato foi a resolução da Coroa lusitana, de transferir a sede do governo, de Salvador para o Rio de Janeiro, em 1763". A essa altura, ao longo do rio, a navegação fluvial já formara um "colar de povoados e vilas".

Pedro II, impressionando com o papel desempenhado na ocupação dos Estados Unidos pela navegação no Rio Mississipi, encomendou a vários técnicos estudos sobre a possibilidade de dar maior importância a esse meio de transporte no São Francisco. E a navegação teve um papel relevante durante 250 anos - principalmente nos oitenta anos que vão do início da navegação a vapor, em 1871, até o declínio na década de 1950, com a discutível escolha que o país fez pelo rodoviarismo. No período de ouro, era uma verdadeira epopéia transportar até o rio as pesadas embarcações de ferro e aço. $\mathrm{O}$ "Presidente Dantas", por exemplo, foi construído no Rio de Janeiro e desmontado. As peças, numeradas, foram de navio para Salvador e de lá, em vagões ferroviários, até Alagoinhas, de onde seguiram em lombo de burro e carros de boi até Juazeiro, para serem remontadas segundo desenhos.

Nessa época de entusiasmo pelas ferrovias e hidrovias, chegou-se a projetar uma ponte de 694 metros em Pirapora, com materiais importados da Bélgica e dos Estados Unidos. A ponte foi inaugurada em 1922, mas acabou sendo uma inutilidade, porque a ferrovia não se completou.

Depois de 1950, vieram as hidrelétricas - Três Marias, Sobradinho, Itaparica, as várias etapas de Paulo Afonso, Xingó. Veio a irrigação de lavouras, a implantação de um pólo de fruticultura, o avanço da soja no Oeste da Bahia. "Na atualidade" - diz o livro - "o panorama da re- gião são-franciscana é o da disputa permanente em torno do uso das águas." E mais uma vez "a nação é mobilizada em favor da causa do rio", em razão do projeto de transposição.

\section{A civilização do São Francisco}

Há todo um capítulo sobre a "civilização do São Francisco", seu isolamento durante trezentos anos, sua permanência à margem do capitalismo, a constituição até de uma linguagem peculiar, a economia quase só de subsistência. E três fatores foram fundamentais para o "delineamento dessa civilização": a implantação do regime de sesmarias pela matriz lusitana - como modelo de ocupação do território e manutenção da soberania -, a pecuária extensiva e "o coronelismo e o compadrio". Disso tudo resultou um modo de vida "assentado em dois esteios - o regime de propriedade privada e o compadrio, os dois pilares da sociedade". Nesse quadro, o São Francisco viu nascer os maiores latifúndios do Brasil, a Casa da Torre (família Garcia d'Avila) e a Casa da Ponte (família Guedes de Brito). Da união entre propriedade privada e família surge a fazenda "como núcleo econômico, social, demográfico e cultural da civilização do São Francisco".

Nesse modelo, o boi - trazido de Cabo Verde - teria papel fundamental. Cento e cinqüenta anos depois da chegada, já eram mais de um milhão de bois na bacia, proporcionando alimento, tração (principalmente para usinas de açúcar), couro. Num modelo de ocupação em que a vontade do "coronel" era lei. E o papel dos tropeiros, fundamental - eram eles emissários oficiais, carteiros, intermediários de negócios, portadores de bilhetes e recados, aviavam mercadorias encomendadas e receitas. Caminhavam de três a seis léguas por dia (dezoito a 36 quilômetros) 
com seus carros de boi. E ainda no Censo de 1950 havia 35.750 carros no Vale do São Francisco, dos quais 60\% em Minas Gerais.

A religiosidade, diz o livro, foi outra marca de sertão. Muito clara nas romarias a Bom Jesus da Lapa, nos movimentos sebastianistas, na devoção ao Padim Ciço, nos episódios de Antônio Conselheiro em Canudos. Outra presença é a de jagunços e cangaceiros, figuras marcantes como Antônio Silvino, Antônio Dó, Virgulino Ferreira da Silva.

Mas há uma transformação radical no panorama, a partir da segunda metade do século XX, com a implantação de hidrelétricas, de Três Marias a Xingó, que vão transformar a paisagem nessa região de 634 mil quilômetros quadrados, $8 \%$ do território brasileiro banhados por um rio de três mil quilômetros de extensão.

\section{Um rio, muitas discussões}

A primeira discussão que se coloca é se o rio deixou de entrar no mar por algumas léguas, como era antigamente, e por quê. O mar de fato está entrando pela foz do rio e destruindo povoações. Embora só haja um registro efetivo de redução nas águas do rio, em 2002, José Carlos Carvalho assegura que sem dúvida há uma diminuição nas águas de nascentes, córregos, riachos, lagoas e afluentes. O geógrafo Pedro Garcia Costa afirma que 350 nascentes, rios e córregos da Bahia secaram em duas décadas.

Uma das teses do livro de Marco Antônio Coelho é de que houve um desvirtuamento nas direções delineadas a partir da Constituição da 1945 e que resultaram na criação da Companhia de Desenvolvimento do Vale do São Francisco (Codevasf). Principalmente por força das teses do economista Lucas Lopes, a geração de energia elétrica no São Francis- co assumiu um papel quase único, que gerou seu "domínio da água", seus projetos de regularização do fluxo do rio para maximizar o aproveitamento hidrelétrico. Hoje, está implantada no rio uma potência de 10,7 mil MW, 15\% do total brasileiro, em uma região com quarenta milhões de habitantes. E são irrigados 340 mil hectares.

A prevalência absoluta do modelo hidrelétrico, com a modificação do fluxo do rio, "foi um golpe arrasador na chamada agricultura de vazante e revelou-se como catastrófico principalmente no Baixo São Francisco". Porque eliminou a possibilidade de plantio nas antigas planícies naturais de inundação. Aumentou a pobreza, a miséria. Além disso, as barragens, aliadas à poluição por esgotos e agrotóxicos, à poluição industrial e à derrubada das matas ciliares, foram desastrosas para a fauna ictiológica do rio, outra fonte de sustento para as populações ribeirinhas.

"O menosprezo pela população do vale" - escreve Marco Antônio Coelho "fica comprovado recorrendo-se a um dado elementar, muito concreto: pelo último Censo Nacional do IBGE, cerca de meio milhão de brasileiros, que residem em povoados situados a pouca distância do Velho Chico, sofrem com a inexistência ou a precariedade do abastecimento de água." E por isso,

tornaram-se um dado trivial corriqueiro os protestos dos são-franciscanos contra a falta de soluções para sua dramática situação [...] Essa grita tão forte é que explica a posição quase unânime do Comitê da Bacia contra o projeto do governo federal de gastar vários bilhões de reais no absurdo projeto de transposição das águas, quando o que sua população reclama e exige é a revitalização do Velho Chico. Daí o repúdio ocorri- 
do nas audiências marcadas pelo Ibama para examinar o malsinado projeto. Assim, somente um insensato não percebe que tal estado de espírito reflete um sentimento arraigado em milhões de brasileiros que vivem no vale e nos sertões do São Francisco.

Um modelo de quinhentos anos

$\mathrm{Na}$ verdade, o projeto da transposição esqueceu-se do fundamental - das realidades do vale e da região do São Francisco. É uma iniciativa que parece ignorar todos os dados da realidade dessa área, em favor de outros interesses, como a expansão de grandes projetos irrigados de fruticultura voltada para a exportação e para a criação de camarões também exportáveis. Ou seja, contribui para a prevalência e expansão de um modelo exportador de produtos primários ou de pequeno valor agregado, para países industrializados - como acontece há quinhentos anos. E como os importadores dominam absolutamente os mecanismos de formação de preços, é preciso exportar cada vez mais para produzir saldos comerciais destinados a equilibrar o balanço de pagamentos e permitir o pagamento de juros cada vez maiores aos mesmos países. Que também detêm o controle dos preços do que exportam para os países "em desenvolvimento" e a eles agregam todos os fatores que desejam - o alto valor de sua mão-de-obra, a remuneração das cadeias de negócios, royalties de patentes etc. Sem falar em que os exportadores arcam com os custos sociais e ambientais, sem nenhuma remuneração.

Para se ter idéia mais concreta desse quadro, basta lembrar que em 1964 o Brasil detinha cerca de $1 \%$ do comércio exterior global. Chegou a 1,5\% em 1985, e hoje está em 1,04\%. Como assinalou o Prof. José Eli da Veiga, da USP, em seu recente livro Desenvolvimento sustentável: desafio do futuro, há produtos exportados hoje por valores reais inferiores aos que vigoravam antes da Grande Depressão do início dos anos 1930. Pode-se acrescentar que a soja brasileira só em 2004 retornou às cotações de 1988, mas já em 2005 chegou a perder $50 \%$ do valor. As carnes brasileiras perderam $17 \%$ do valor real em uma década e estão, neste início de 2006, no mais baixo preço de muitas décadas.

Não é, portanto, essa transposição que enfrentará os problemas centrais e cruciais. A prioridade - agora é o autor do livro que fala - precisa ser a revitalização. Mas em 2003 só foi feito nessa direção $1 \%$ do que seria indispensável - e nesse passo o processo lavará um século.

Não bastasse isso, lembra o livro, o projeto da transposição consagra uma interferência indevida do Ministério da Integração Nacional nas funções do Ministério do Meio Ambiente, onde se situa o Ibama, o órgão licenciador. Esse vale a pena lembrar - teve sua autonomia gravemente atingida pela própria ministra do Meio Ambiente, que deu seu apoio prévio, público, ao projeto de transposição, antes que o Ibama nem sequer houvesse examinado o estudo de impacto ambiental. Além disso, o MMA cerrou fileiras a favor da aprovação do projeto no Conselho Nacional de Recursos Hídricos.

\section{Um ectoplasma sobre o Brasil}

Depois das profundas distorções geradas pela prevalência do modelo hidrelétrico (que ainda determinou o deslocamento de 72 mil pessoas que habitavam áreas de inundações), sobrevém a projetada transposição, "um ectoplasma que paira sobre o Brasil" (diz o autor) desde o século passado. Mas um ectoplas- 
ma fortemente apoiado em lobbies políticos e econômicos, que fazem o projeto ressuscitar de tempos em tempos, governo após governo - e que já permitiu gastar R \$ 70 milhões de recursos federais em consultorias antes de feita qualquer obra.

Na versão mais recentes, do atual governo, o projeto é capitaneado pelo $\mathrm{Mi}$ nistério da Integração Nacional, embora até um documento da liderança da bancada do Partido dos Trabalhadores na Câmara dos Deputados considerasse "inviável o apoio" do partido a essa proposição.

Basicamente, o projeto do MIN argumenta:

a) a transposição é indispensável para resolver a situação de doze milhões de pessoas no Nordeste Setentrional;

b) prevê retirar apenas $1 \%$ da vazão do São Francisco, que não prejudicaria a utilização já existente;

c) o custo é muito baixo, pois evitará as despesas de quase todo ano no socorro a flagelados da seca;

d) só haverá utilização maior de águas quando o nível do reservatório de Sobradinho estiver acima de $94 \%$.

O livro, escorado em argumentos e pareceres de numerosos especialistas, refuta todos esses pontos. Como já foi exposto, entende que o projeto parte de uma análise equivocada dos problemas do semi-árido. Investirá vultosos recursos para beneficiar um grupo muito pequeno. $\mathrm{O}$ desvio será prejudicial às populações ribeirinhas e nocivo ao desenvolvimento das unidades da federação banhadas pelo rio. A conduta do governo federal, ao tentar impor seu projeto, é autoritária e viola a legislação sobre recursos hídricos.
Em apoio à sua tese de que a análise do semi-árido contida no projeto é equivocada, lembra as teses de Celso Furtado, para quem o essencial é aprender a conviver com o semi-árido, não propriamente modificar a realidade física. $\mathrm{Na}$ versão atual, o projeto mantém as estruturas que perpetuam a "indústria da seca". $\mathrm{E}$ atribui todo o problema do semi-árido à estiagem, sem referência a fatores sociais, econômicos e políticos. A falta de água é que seria o obstáculo do desenvolvimento - esquecendo todos os fatores já comentados.

"Se água fosse o mais importante" cita o livro nas palavras de Manoel Duque - " "as margens do São Francisco e do Parnaíba seriam vergéis, quando são dois desertos, e o Maranhão chuvoso seria próspero." Também era essa a opinião de Celso Furtado, para quem a pobreza é conseqüência do subdesenvolvimento, da exploração da região por uns poucos grupos do Nordeste e de outras partes do país: "A escassez de água" - escreveu ele "é apenas um dos componentes do problema. Sabemos que se chovesse o dobro a região possivelmente seria ainda mais pobre - a erosão tudo destruiria, inclusive a caatinga".

Celso Furtado entendia - e escreveu isso em 1998 - que o projeto da transposição era "uma panacéia. Porque ninguém dizia quanto custaria, por que beneficiaria prioritariamente proprietários de terras". Perguntava se eles teriam "novos açudes para evaporar" (e, de fato, a maior parte da água se destinará a açudes já existentes). "O problema" - disse ele - "não está em ter mais água, mas em usar bem a água que já existe.”

\section{Homenagem do vício à virtude}

O livro de Marco Antônio Coelho observa que o governo federal decidiu dar 
o nome de Celso Furtado ao canal Norte da transposição, confirmando o ditado popular de que "a hipocrisia é a homenagem do vício à virtude".

A pergunta de Celso Furtado, se haverá novos açudes para evaporar, é respondida no livro pelo professor Alberto Daker, da Universidade Federal de Viçosa, ao lembrar que existem no Nordeste mais de setenta mil açudes particulares de pequeno e médio portes, e mais de quatrocentos açudes públicos de médio e grande portes, com capacidade de armazenamento total de cerca de trinta bilhões de metros cúbicos, maior que a da barragem de Três Maria (cerca de 21 bilhões) e quase igual ao da grande barragem de Sobradinho, uma das maiores do mundo (cerca de 34 bilhões). E como os proprietários privados temem atraso nas chuvas ou que as águas dos açudes sejam insuficientes, elas "são usadas com muita parcimônia", aumentando a evaporação e não abastecendo a população sertaneja. Essas águas já represadas seriam suficientes para irrigar 480 mil hectares de terras, mas só irrigam 120 mil. E são esses açudes que receberão a maior parte das águas transpostas.

Por essa e outras razões, a Comissão Pastoral da Terra diz que $70 \%$ dos açudes públicos não estão disponíveis para a população. E o Prof. Aldo Rebouças, da USP, tem repetido que o problema do semi-árido não é exatamente falta de água, e sim gestão deficiente. O Departamento Nacional de Obras contra a Seca lembra que só no Vale do Jaguaribe as águas de chuvas que podem ser armazenadas são suficientes para irrigar 140 mil dos 220 mil hectares de solos irrigáveis ali existentes.

Também a Universidade Federal do Rio Grande do Norte - outra informa- ção do livro - considera suficiente a água que existe no estado. Só os 2,4 bilhões de metros cúbicos do açude Açu seriam suficientes para abastecer a população do Rio Grande do Norte durante vinte anos mas prevê-se abastecer o estado com águas transpostas do São Francisco. Já a área do Seridó, que carece de água para irrigação, não foi contemplada no projeto "com uma gota sequer das águas do Velho Chico".

A transposição, assegura o livro, "apenas beneficia uma minoria de privilegiados", a começar pelos grupos de consultores, passando pelas empresas construtoras e chegando aos fornecedores de equipamentos.

Para evitar danos maiores, Celso Furtado já propunha que se desapropriassem as terras beneficiadas ao longo dos canais da transposição. Na nova versão do projeto - diz o livro - consta apenas que cabe ao Incra "fazer o levantamento da estrutura fundiária para fins de reforma agrária". Um decreto considerou de utilidade pública para desapropriação com fim social cinco quilômetros de terra nas margens dos canais; são 350 mil hectares, dos quais, segundo o MIN, “50 mil próprios para agricultura serão utilizados pelo $\mathrm{Mi}$ nistério do Desenvolvimento Agrário para projetos de reforma agrária".

Tantas questões levaram a própria Sociedade Brasileira para o Progresso da Ciência (SBPC), numa reunião em Recife, a afirmar que o projeto do Eixo Norte da transposição não comprova a necessidade social e a viabilidade econômica; o Eixo Leste pode ter justificativa.

E tantos argumentos levaram três governadores - Minas Gerais, Bahia e Sergipe - a posicionarem-se contra a iniciativa. O de Minas a questiona no Supremo Tribunal Federal. Os governadores 
da Paraíba, Ceará e Rio Grande do Norte, estados receptores de futuras águas transpostas, são a favor.

O Comitê de Gestão da Bacia do São Francisco tomou posição frontalmente contrária, porque o projeto "viola os princípios do Sistema Nacional de Gerenciamento de Recursos Hídricos". A Associação Brasileira de Engenharia Sanitária também se manifestou contrária, assim como conselhos regionais de engenharia e arquitetura (Crea), a Comissão Pastoral da Terra, o Ministério Público em vários estados. Até a Conferência Nacional do Meio Ambiente posicionouse contrária (27.11.2003), lembra o livro. Mas nada disso impediu a Agência Nacional de Águas de autorizar o projeto.

Para completar os argumentos contra o projeto enumerados pelo livro: segundo o Prof. João Abner, da UFRN, só 5\% do semi-árido serão beneficiados pela transposição, que nenhum benefício trará para as populações mais necessitadas, em áreas difusas; essas, segundo a Caritas, poderiam ser beneficiadas, a um custo muito menor que o da transposição, pela implantação de um milhão de cisternas para reter águas de chuvas, para seis milhões de pessoas.

\section{Três depoimentos contundentes}

Chega-se então, no livro, a três depoimentos muito contundentes - o do secretário e ex-ministro José Carlos Carvalho (MG) e os dos governadores Paulo Souto (BA) e João Alves Filho (SE).

$\mathrm{O}$ primeiro, em pronunciamento na Comissão Especial da Câmara dos Deputados, desmontou, um a um, os argumentos favoráveis à transposição, e mostrou que as causas dos problemas no semi-árido estão, como já foi apontado, nos desequilíbrios regionais e nos desníveis sociais. A seu ver, não serão afastados por uma falsa solução, que ainda prejudicará as populações que vivem nas margens do Rio São Francisco e nas proximidades dos açudes nordestinos. Não bastasse isso, $\mathrm{O}$ projeto proverá água a preços mais altos que $\mathrm{o}$ dos projetos à margem do rio, $\mathrm{e}$ imporá novos custos aos usuários urbanos da água.

Observa ele que a licença prévia concedida pelo Ibama "embora com 31 condicionantes, não traz uma linha sequer, absolutamente nada, sobre o rio São Francisco, como se não existisse um rio a montante dos pontos de captação [...] Todas as demandas ambientais do Velho Chico foram sumariamente ignoradas".

Contesta também que a transposição só utilizará $1 \%$ da vazão do rio. E lembra que a utilização maior, só quando Sobradinho estiver com mais de $94 \%$ do reservatório plenos de água, implica que os custos para uma captação maior ficarão ociosos em $60 \%$ do tempo (num projeto de R \$ 4,5 bilhões só para os canais, sem contar obras para fazer a água chegar às casas dos cidadãos). E mesmo considerando a área de influência indireta do projeto, "a mais ampla, ele não chega a $20 \%$ da superfície da região semi-árida".

São muitos e contundentes os argumentos nesse depoimento. Vale a pena lê-los na íntegra, se se quiser ter idéia das incongruências do projeto.

Já o governador Paulo Souto começa lembrando que o próprio Banco Mundial não se interessou em financiar a obra, "por não considerá-la prioritária, por apresentar custo elevado e ser pouco eficaz no combate à pobreza". Segundo o governador da Bahia, "a água transposta do São Francisco custará R 0,11 por metro cúbico (dados do projeto). É a água destinada à irrigação mais cara do mundo, pois nesse valor não se inclui a derivação 
final até a propriedade que dela fará uso. Essa cifra corresponde ao custo da água entregue pelas obras-tronco, simplesmente, e é cinco vezes mais caro que a água utilizada pelos projetos da Codevasf".

Não bastasse tudo isso, o Ceará, diz ele, dispõe de quatro vezes o volume de água de que necessita - sem precisar da transposição -, e o Rio Grande do Norte, de duas vezes. Já o Eixo Leste pode, em sua opinião, justificar-se diante das carências no agreste de Alagoas, Pernambuco e Paraíba - mas "existem alternativas técnicas mais baratas que o projeto da transposição". E há projetos de irrigação na Bahia Salitre, Baixo Irecê, paralisados porque faltam recursos.

Diz o governador João Alves Filho, em seu depoimento transcrito no livro, que jamais viu "tamanha insensatez e inabilidade" quanto no projeto da transposição, "destinado, em sua maioria, não ao consumo humano ou animal, mas à criação de camarão e à irrigação". Cita ele os problemas e malogros de vários grandes projetos de transposição de águas para irrigação no mundo - Estados Unidos, China, Rússia -, e assegura que o projeto brasileiro "vai atingir apenas cinco por cento da população do semi-árido nordestino".

\section{A obrigação de responder}

Enfim, as 272 páginas do livro de Marco Antônio T. Coelho trazem um volume impressionante de informações sobre o problema - tanto no contexto da bacia do São Francisco como no semi-árido -, e sobre a pretendida solução de transpor águas. Ao final, a proposta parece arrasada.

É inacreditável que o governo federal continue a ignorar todos esses argumentos, sem respondê-los, simplesmente tentando desqualificar os críticos e opositores.
O livro, entretanto, habilita a sociedade brasileira a informar-se, discutir. E exigir respostas dos seus governantes. É um serviço inestimável. E competente.

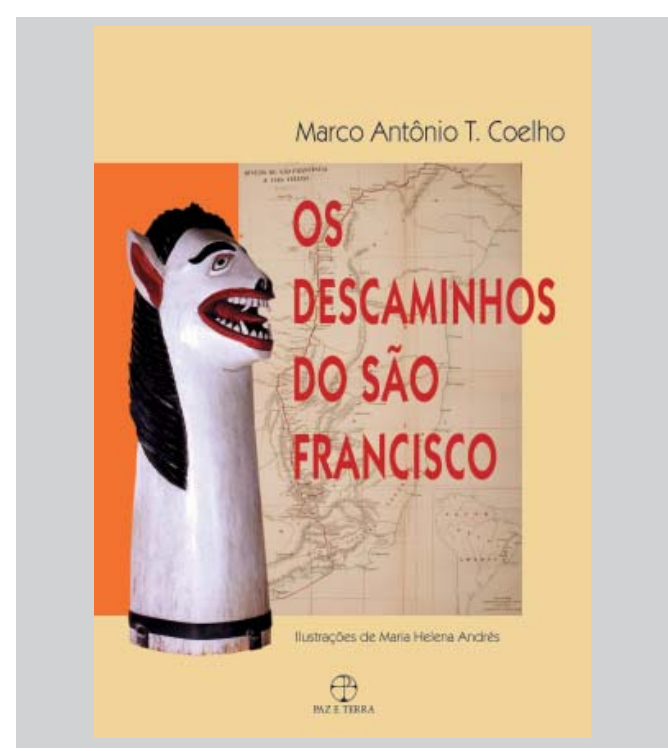

COELHO, M. A. T. Os descaminhos do São Francisco. Prefácio de José Carlos Carvalho; ilustrações de Maria Helena Andrés. Rio de Janeiro: Paz e Terra, 2005. 272p. mais fotos.

Washington Novaes, jornalista, é consultor ambiental e ex-secretário de Meio Ambiente, Ciências e Tecnologia de Brasília (DF). @ - wlrnovaes@uol.com.br 